\title{
Sensitivity Analysis of Building Envelop Elements Impact on Energy Consumptions Using BIM
}

\author{
Cheng Zhang, Lijing Ong \\ Department of Civil Engineering, Xi'an Jiaotong-Liverpool University, Suzhou, China \\ Email: cheng.zhang@xjtlu.edu.cn, lijing.ong15@student.xjtlu.edu.cn
}

How to cite this paper: Zhang, C. and Ong, L.J. (2017) Sensitivity Analysis of Building Envelop Elements Impact on Energy Consumptions Using BIM. Open Journal of Civil Engineering, 7, 488-508. https://doi.org/10.4236/ojce.2017.73033

Received: August 17, 2017

Accepted: September 23, 2017

Published: September 26, 2017

Copyright $\odot 2017$ by authors and Scientific Research Publishing Inc. This work is licensed under the Creative Commons Attribution International License (CC BY 4.0).

http://creativecommons.org/licenses/by/4.0/ (c) (i) Open Access

\begin{abstract}
Lots of researches have shown that the optimization of building envelope reduces building energy consumption during its lifecycle. Due to the uncertainty of the relationship between individual design parameters and building performance, the extent of impact cannot be well-understood. Therefore, it is essential to evaluate the impact extent for different design parameters and identify the one (s) that impact (s) more to the building performance and hence focus so as to improve building performance efficiently. In the present research, main design parameters that affect the building performance are selected to analyse the extent of the impact. Material quantities are extracted directly from the Building Information Modelling (BIM) model so as to calculate the embodied energy in material. Moreover, simulation of energy consumption is run for different scenarios during operation stage. Energy embodied in typical construction materials are calculated for each scenario accordingly. Finally, sensitivity analysis is applied to find the extent of impact on life cycle energy of building for the selected design parameters in terms of both embodied energy (EE) and operational energy (OE). A case study of a manufactory plant is carried out to investigate the impact of the selected design parameters.
\end{abstract}

\section{Keywords}

Sensitivity Analysis, Building Envelop, BIM, U-Value

\section{Introduction}

The optimization of building envelope often involved the analysis of multi-design parameters (elements of building envelope) together to investigate the op- 
timal design scheme that can achieve both cost-saving and reduce energy consumption. The traditional optimization process is time-consuming and complicated since it is generated by the interactions between different design parameters. Besides, previous studies [1] [2] [3] [4] have often performed optimization process based on the thermal properties improvement of design parameter (i.e. U-value of envelope elements, Window-Wall-Ratio (WWR), etc.); however, in some circumstance, the production of building envelope elements with better thermal performance often involved energy-intensive construction processes which would increase the $\mathrm{EE}$ of buildings. In this case, the optimization process is not energy-efficient, i.e. using more EE to achieve OE saving. Therefore, the additional energy required needs to consider along with the lifecycle of building to determine the true benefit gains from the optimization of building envelope [5].

In addition, due to the complexity of building nature and occupants behaviour, the relationship between design parameters and building performance is often uncertain and if the uncertainty of impact factors can be well-understood, the building performance can easily be improved by carefully choosing important design parameter and hence focus [6]. The elements of building envelope are positioned in different parts of building and together build up the envelope of building. Considering various relative different thermal properties of element materials and proportion of elements within building envelope yield different energy demands during construction and operational stages, the purpose of this research is to investigate how the thermal properties of each envelope element impacts energy demand in a building with the aid of building information modelling (BIM) tools and to identify which envelope element has the most influential impact on lifecycle energy of building by performing sensitivity analysis (SA). This research proposed to carry out SA based on EE by measuring the correlation degree between $\mathrm{EE}$ and $\mathrm{OE}$ in building for each envelope element in order to understand the impact of EE variation due to thermal properties of element changes on the OE of building and relative importance of envelope elements in term of EE. From the proposed EE based SA, the energy-efficiency of envelope element in reducing lifecycle energy (LCE) of building can then be identified. With the aid of BIM as a platform to perform SA, it is expected that this research can provide information to facilitate designers to make better decision on prioritizing the optimization target in selecting efficient building envelope design that improve building's environmental performance, reduce energy cost and resource waste during the operational stage, and finally lead to the creation of truly green building.

The objectives of this paper are: 1) to investigate how the thermal performance of each envelop element impacts building energy consumptions; 2) to measure the correlation degree between embodied energy and operational energy in building for each envelop element; and 3) to identify which envelop ele- 
ment has the most influential impact on life cycle energy of building by performing sensitivity analysis.

\section{Literature Review}

Over the last years, there are great numbers of research focused on the building envelope optimization. Many measures have been proposed and assessed from the view of economic, energy efficiency and resource conservation. Pikas et al. [3] concluded that windows and walls with smaller U-value are more energy efficient and they have proposed a cost optimal design solution with net present value up to $349.40 \mathrm{Euro} / \mathrm{m}^{2}$. The proposed building envelope design optimization strategy by Liu et al. has reduced the lifecycle cost and lifecycle carbon emission of building by $29.83 \%$ and $30.44 \%$, respectively [4]. In the study of Sakar and Bose (2016), the application of insulation on wall and roof have significantly reduce the space heating by $40 \%-60 \%$, cooling by $25 \%-40 \%$ and mechanical ventilation by $25 \%$. The annual energy consumption was reduced by around 25\%. Huang et al. [2] studied the impact of window U-value and wall insulation material thickness on building energy consumption by comparing lifecycle energy cost saving. They revealed that window with higher $U$-value and wall with thicker insulation is more energy-saving design than those of lower $\mathrm{U}$-value and thinner insulation. This is due to higher cost of window with better thermal performance.

From literature review, lowering U-value of building envelope can reduce the heat losses during winter and heat gains during summer efficiently, as a result reduce energy consumption during building operational stage. Therefore, a summary can be drawn: the thermal properties of building envelope are correlated with building energy used in the later operational stage: the lower the $\mathrm{U}$-value, the less amount of operational energy required. However, the production of building envelope elements with better thermal performance often involved energy-intensive construction processes. Hence, the additional energy required needs to consider along with the lifecycle of building to determine the true benefit from the optimization of building envelope.

Embodied energy (EE) in construction material and operational energy (OE) are the two major lifecycle energy (LCE) of building and the total of these two energy can constitute up to $90 \%$ of LCE demand with other LCEs being insignificant (maintenance and demolition energy), therefore, great deal of effort have been carried out to focus on the reduction of $\mathrm{EE}$ and $\mathrm{OE}$ during the lifecycle of building. EE is the total energy required for the processes of construction stage such as building material production, transportation and assembly onsite. While OE represents the energy used during operational stage of building to meet various requirements such as heating, cooling, ventilation, water heating and electrical appliances (such as lighting, escalator, etc. [7] [8] [9]).

As mentioned, building envelope plays an essential role to lower energy consumption of building and it is mainly associated with both construction and op- 
erational stages in lifecycle of building. During construction stage, the production of building envelope material (brick, cement, steel and etc.) represents the main contributor to $\mathrm{EE}$ in building. The $\mathrm{EE}$ of building envelope can constitute up to $45 \%$ of LCE demand in building, therefore careful selection of building envelope materials with consideration of their $\mathrm{EE}$ is crucial for minimizing $\mathrm{EE}$ in building and hence, reduce LCE of building as well [7] [10]. During operational stage, the building envelope significantly impacts the heating/cooling load in building and contributes to LCE in building. In the U.S. building sector, around $50 \%$ of the heating load and $30 \%$ of the cooling load in residential buildings are conducted through walls, foundations, and roof; and $43 \%$ of the energy in residential building is consumed for space heating and cooling [11]. Therefore, a well-designed building envelope can reduce LCE of building efficiently by reducing the demand of $\mathrm{OE}$ and the energy saving perspective can be addressed in two ways: minimize heat losses from the indoor of building and manage solar heat gains [12].

Previous studies often revealed that EE of a building was small as compared to OE across its lifecycle [9]. For example, Cole and Kernan [13] have modelled a typical office building to study the relationship between OE and EE and found that $\mathrm{EE}$ is fairly small as compared to $\mathrm{OE}$ and will be overtaken by $\mathrm{OE}$ in early of the building life. The study of Adalberth estimated that $11 \%$ and $84 \%$ of 50 years LCE in a single-unit dwelling is EE and OE respectively. This indicates that targeting on minimizing $\mathrm{OE}$ is way more effective than $\mathrm{EE}$ in reducing total LCE [14]. However, current interest has slowly shifted toward EE due to the effectiveness of advanced economic measures in reducing OE of building such as energy efficient equipment, renewable energy technologies and insulating materials and also these measures would increase the material used [9]. For example, the production of element with lower $\mathrm{U}$-value is an energy-intensive process due to addition of insulation materials for better thermal performance; thereby EE is considerably increased while increasing the material consumption to satisfy the target thermal properties. This concludes that EE increases while attempting to minimize OE in building [2] [7] [9] [15]. The research carried by CSIRO found that as the building becomes more energy efficient, EE in building will approach about half of the LCE [16]. The finding of Thormark [17] also agreed with this concept as his research stated that EE of a low energy building could range between $40 \%-60 \%$ of LCE. In order to reduce the total LCE in building, EE needs to be considered along with OE. In some circumstances, high EE in efficient building envelope elements (such as triple-glazed windows) can be trade off from the saving in energy cost during operational stage and downsized of HVAC system. Therefore, a truly holistic approach is necessary in analysing the LCE of buildings.

In the optimization of building envelope, EE of element are considerably increased while increasing the material consumption to satisfy the target thermal properties and reduce $\mathrm{OE}$ in buildings. Therefore, in order to reduce the total 
LCE in building, EE needs to be considered along with OE. Considering various relative thermal properties of different materials and the proportion of envelope elements within building yield different energy demand during operational stage, sensitivity analysis was proposed as a tool in this research to measure the correlation degree between $\mathrm{EE}$ of building envelope and $\mathrm{OE}$ of building and also used to understand the uncertainty between thermal properties of envelope elements and $\mathrm{EE}$ of building envelope and its impacts on building performance.

\section{Methodology}

The research methodology, as shown in Figure 1, was proposed to meet the objectives of this research with the aid of sensitivity analysis and BIM tools as a platform. The design parameters to study were first identified in the research. Then, the base model of building was created by using BIM and the properties of building were defined in the model. Next, the energy baselines were calculated upon the base model, include operational energy (OE) and embodied energy (EE). The energy analysis was run iteratively by varying one or more design parameters while all other parameters were set to be constant. The output result of interest is the energy used in the building during its lifetime operational stage, i.e. operational energy (OE), assuming the lifetime of building is 50 years. With respect to each design parameter changes, the information of energy used in building were obtained from the simulation output result and the EE of building envelope was calculated based on the quantity and energy coefficient of materials. Lastly, the correlation degree between $\mathrm{OE}$ and $\mathrm{EE}$ for each envelope element respect to the design parameter was measured and compared to identify the most influential design parameter which is the one that the output results have highest degree of variation with respect to its change. A sensitivity indicator was chosen to represent the sensitivity results, which provide the importance of design parameter to OE of building in term of LCE.
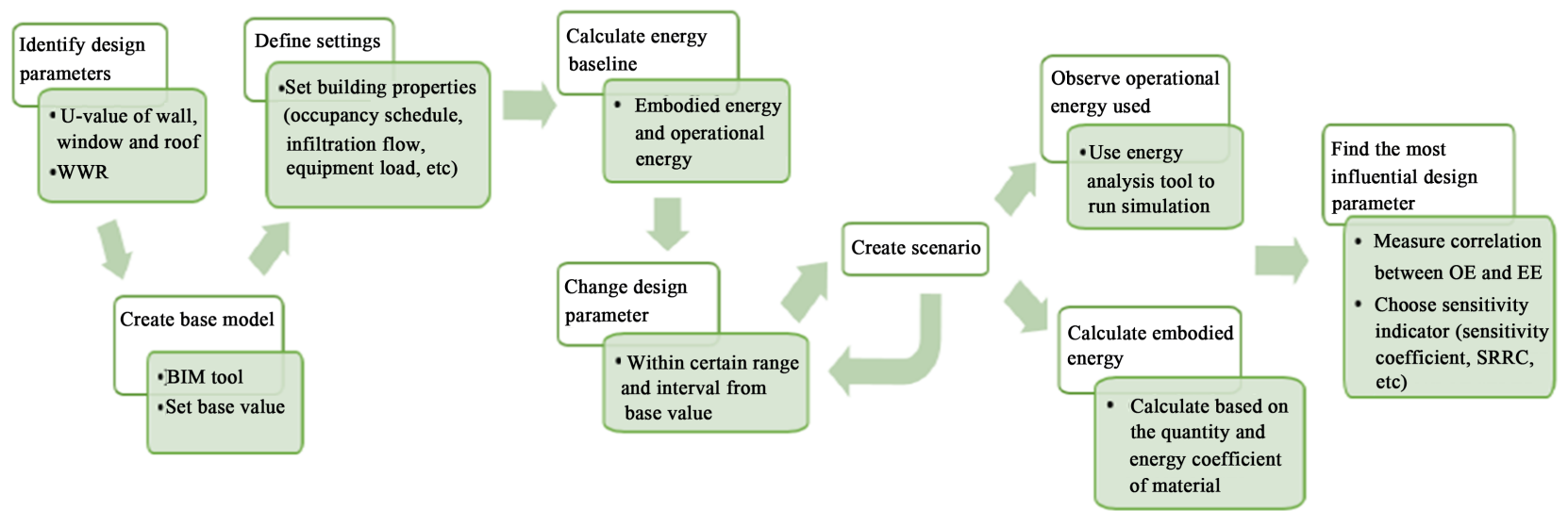

Figure 1. Framework of research methodology. 


\subsection{Identification of Design Parameters}

According to literatures, thermal properties of external building envelope, i.e. wall, windows and roof, are the most influential factors affecting energy consumption in buildings during operational stage since the heating and cooling loads in buildings are transferred externally through building envelope from exterior environment [1] [18]. Therefore, the design parameters of interest selected for this research are the thermal properties of wall, windows and roof. The thermal properties of building envelope are generally expressed as $\mathrm{U}$-value $\left(\mathrm{W} / \mathrm{m}^{2} \cdot \mathrm{K}\right)$ which is the amount of heat energy transfer through a building envelope element. In addition, window to wall ratio (WWR) has significant impact on building energy consumption for HVAC system as windows and walls contribute to heat gain and loss in building, either from sun or through conduction, and the amount of heat gain or loss is dependent on the area and thermal properties of windows and walls. Therefore, WWR is also included as design parameter in this research.

\subsection{Creation and Setup of Base Model and Energy Consumption}

The base model of a building was created by using BIM tools. The building energy consumption baseline ( $\mathrm{OE}$ and $\mathrm{EE}$ ) was calibrated by the design parameters and properties of base model building. The $\mathrm{EE}$ of base building envelope and $\mathrm{OE}$ of base model from energy analysis are used as energy baseline values for comparison in the SA. The embodied energy (EE) associated with building envelope elements is estimated based on energy coefficient, density and volume of the elements. Table 1 tabulates the energy coefficient of typical construction materials which are obtained from the Inventory of Carbon \& Energy database (ICE) and it represents the total energy used in the direct and indirect processes to produce the materials within the boundaries of cradle-to-gate [19]. While the volume of element can be extracted from the quantity take off function of BIM. By multiplying the volume of elements $\left(\mathrm{m}^{3}\right)$ by the density of element $\left(\mathrm{kg} / \mathrm{m}^{3}\right)$ and the energy coefficient of element $(\mathrm{MJ} / \mathrm{kg})$, the $\mathrm{EE}$ of building envelope element (MJ) is obtained.

The $\mathrm{OE}$ of building is dependent on the type of building, the building properties, such as density of people, occupancy schedule during weekday and weekend, infiltration flow and equipment load (computer, lighting, etc.) and these

Table 1. Energy coefficient of typical construction materials (selected from ICE [19]).

\begin{tabular}{cc}
\hline Construction Materials & Energy coefficients $(\mathrm{MJ} / \mathrm{kg})$ \\
\hline Bricks & 3.00 \\
Cement & 4.60 \\
Concrete & 0.95 \\
Glass & 15.00 \\
Timber & 8.50 \\
\hline
\end{tabular}


properties are defined in the model. These building properties are used to calculate the internal heat gain in building and subsequently compute the energy consumption for equipment and HVAC system to maintain thermal comfort within the building [18]. Energy analysis tool embedded in BIM is used to simulate the energy used in building during operational stage. For example, Green Building Studio (GBS) is the popularly used tools for energy analysis.

\subsection{Variation of Design Parameter}

To perform SA, the design parameters were varied in the model from baseline value within certain range and interval to create different scenarios, while other design parameters were fixed to its base model value.

Table 2 tabulates the typical range and recommended maximum value by GB50189-2015 for the design parameters [8] [20] [21] [22] [23]. According to literature, the $\mathrm{U}$-value of walls and roof are affected by thermal mass and insulation whereas for windows, the glazing type and number of layer are the impact factors to consider. Based on the understanding, the design parameters were then varied by focusing on these factors.

To simplify SA process and to understand the individual impact of thermal mass on U-value exclusively, the insulation for walls and roof are ignored in this research and merely focused on the thermal mass of element, therefore the considered factor impacts $U$-value of elements is the thermal properties of material. By changing the thickness of the wall and the roof to meet corresponding $\mathrm{U}$-values, different scenarios are created. Depending on glazing type and the number of glazing layer, the $\mathrm{U}$-value of windows was modified by varying the thickness of glass plane, which is the traditional variable of windows [24]. The U-value of the window is calculated by using Equation 1:

$$
R_{1}+R_{2}+\cdots+R_{n}=n \frac{t_{g}}{K_{g}}+(n-1)\left(\frac{t_{a}}{K_{a}}\right)=\frac{1}{U}
$$

where $t_{g}$ is the thickness of glass $(\mathrm{mm}) ; K_{g}$ is the thermal conductivity of glass $(\mathrm{W} / \mathrm{m} \mathrm{K}) ; t_{a}$ is the air space of inert gas $(\mathrm{mm}) ; K_{a}$ is the thermal conductivity of inert gas $(\mathrm{W} / \mathrm{m} \mathrm{K}) ; \mathrm{n}$ is the number of glazing layer. In this research, the glazing type of windows was kept to be the same when varying the thickness of glass plane to ignore the impact of glazing type on $U$-value of windows. According to literatures, for glazing with two or more layer, the ratio of air space between

Table 2. Typical range and recommended maximum value.

\begin{tabular}{cccc}
\hline \multicolumn{2}{c}{ Design parameters } & Typical range & GB50189-2015 recommended maximum value \\
\hline & Wall & $0.37-1.95$ & 0.5 \\
U-value & Window & $1.70-6.00$ & 3.5 \\
$\left(\mathrm{~W} / \mathrm{m}^{2} \cdot \mathrm{K}\right)$ & Roof & $0.18-3.00$ & 0.8 \\
& & $0.10-1.00$ & - \\
\hline
\end{tabular}


glass plane $\left(t_{a}\right)$ and thickness of glass $\left(t_{g}\right)$ was generally to be 2:1 [25] [26]. Therefore, the air space was assumed to be twofold of the glass thickness:

$$
t_{a}=2 t_{g}
$$

Based on this assumption, the required thickness for glass $\left(t_{g}\right)$ can then be solved by Equation 3 with the known properties of glazing and inert gas between glass plane to achieve target $\mathrm{U}$-value:

$$
t_{g}=\frac{1}{(U)\left(\frac{n}{K_{g}}+(n-1)\left(\frac{2}{K_{a}}\right)\right)}
$$

In this research, different window to wall ratios (WWR) are to be examined to study their impact on building energy consumption. The typical WWR is range from $0.10-1.00$, as shown in Table 2. It is defined as the ratio of window area $\left(A_{w d}\right)$ to wall area $\left(A_{w}\right)$. The target WWR can be achieved by changing the size and number of windows. In this research, the latter was used as the approach to vary WWR.

\subsection{Sensitivity Analysis}

Sensitivity coefficient (SC) and standardized regression coefficient (SRC) were selected as local sensitivity indicator and global sensitivity indicator respectively to measure the sensitivity of different design parameters on $\mathrm{OE}$ of building and its energy-efficiency. SC has been used frequently in the field of statistics and was used only for local sensitivity analysis (LSA) in this research, which varying one design parameter at one time while other parameters kept being constant. It is used to measure the impact degree of each design parameter value on the building energy used and it is a dimensionless value that defined as ratio of output value changes (building energy used) to input value variation (design parameter). If SA involves only one step change, the change is calculated with respect to base model value and SC can be calculated by Equation 4 . If the input parameter has more than one data set, SC can be determined from the gradient slope of the data set which also can demonstrate its correlation [27].

$$
\mathrm{SC}=\frac{\left(E_{f}-E_{i}\right)}{\left(D P_{f}-D P_{i}\right)}
$$

where SC is the sensitivity coefficient; $D P_{f}$ is the design parameter value; $D P_{i}$ is the base value of design parameter; $E_{f}$ is the output value when the design parameter is $D P_{b} E_{i}$ is the output value of base model.

Since the design parameter was varied within certain range and interval, the input parameter would then has more than one data, therefore the graphs of building energy used respect to each input design parameter were plotted and obtained the corresponding gradient slope. The obtained values were compared to study the relative importance and correlation of design parameter to the output results (OE of building). The latter was measured and presented as coeffi- 
cient of determination $\left(\mathrm{R}^{2}\right)$. Similarly, the correlation degree of OE and EE can be measured by plotting the graph of $\mathrm{OE}$ versus $\mathrm{EE}$ and determined from the gradient slope of the graph. Higher SC value indicates that the design parameter is more important and sensitive [27].

For Global Sensitivity Analysis (GSA), the correlation degree between input and output was evaluated by varying more than one input parameters simultaneously. SRC is used as the quantitative measure of GSA in this research through linear regression approach [6]. The general form of a linear regression model is as follows:

$$
y(x)=b_{0}+\sum_{i=1}^{n} b_{i} x_{i}
$$

where $y$ is the output value, $b_{i}$ is the linear regression coefficient and $x$ is the input value. Then, the SRC can then be calculated by standardizing the linear regression coefficient by the standard deviation $(\sigma)$ of input and output values:

$$
\mathrm{SRC}=\frac{b_{i} \sigma(x)}{\sigma(y)}
$$

Positive SRC value means that the input parameter has positive impact on the output result, which increasing the parameter would lead to an increase of the dependent output result; negative SRC means that with the increase in the parameter, the output result is decreased [18].

\section{Case Study}

The case study building is a 3-storey industry currently constructing in SuZhou. The 3D model of a manufacturing building was created by using Autodesk Revit. While the building energy analysis was performed by Energy Analysis (EA) add-in tool in Revit, which links the design feature of the model to analysis feature of Green Building Studio (GBS). The energy simulation performed in GBS uses DOE2 simulation program to run building model simulation with the purpose of producing sustainable and energy efficiency design in the earlier stage [28]. This program has been used widely to perform energy modelling and its accuracy and consistency have been validated. However, DOE2 has limitation in dealing with complicated model that consists of large number of data required to handle and analyze [27]. Therefore, to guarantee robustness and consistency, the model was simplified to consider only first floor of case study building for energy simulation. Figure 2(a) shows the BIM model of case study building and Figure 2(b) presents the simplified first-storey model that was used for energy simulation in the research.

The energy settings were defined in Revit, which includes building type, ground plane, location and other parameters. These parameters were fixed constant except the design parameters of interest to ensure the reliability of output results. By changing the design parameters within certain range and interval as shown in Table 2, 25 scenarios in LSA and 62 scenarios in GSA were created and the energy simulation were applied. Table 3 summarizes the material properties 


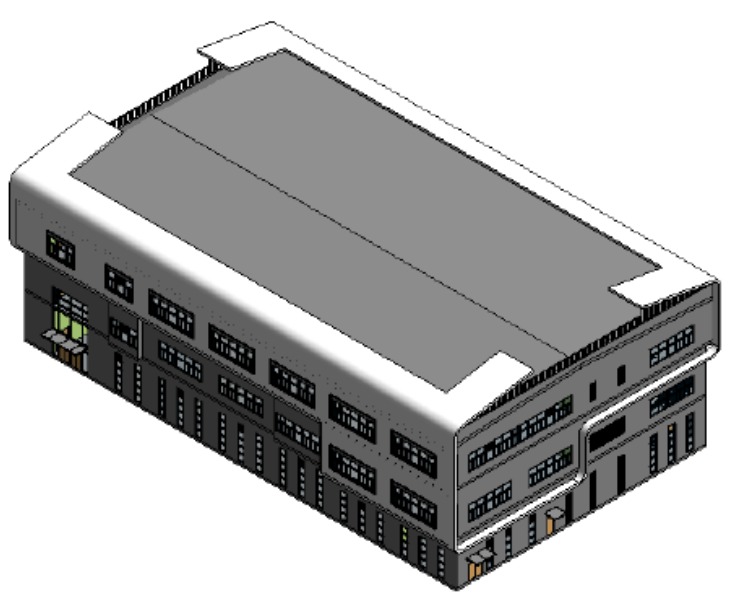

(a)

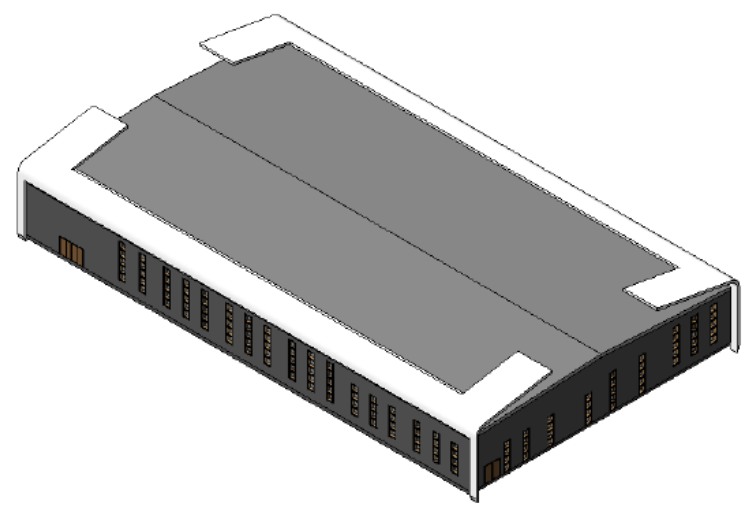

(b)

Figure 2. Base model and simplified model.

Table 3. Material properties.

\begin{tabular}{cccc}
\hline Material & $\begin{array}{c}\text { Thermal conductivity } \\
(\mathrm{W} / \mathrm{m} \mathrm{K})\end{array}$ & $\begin{array}{c}\text { Energy coefficient } \\
(\mathrm{MJ} / \mathrm{kg})\end{array}$ & $\begin{array}{c}\text { Density } \\
\left(\mathrm{kg} / \mathrm{m}^{3}\right)\end{array}$ \\
\hline Light weight concrete & 0.209 & 0.95 & 950 \\
Autoclaved aerated concrete & 0.210 & 3.50 & 580 \\
Glass & 1.100 & 15.00 & 2480 \\
Air & 0.025 & - & - \\
\hline
\end{tabular}

of building envelope elements considered to calculate the embodied energy and required thickness of element to achieve target $\mathrm{U}$-value.

The thermal conductivity and density of material were extracted from Autodesk Material Library which is a CIBSE standard system library. From these data, the corresponding total embodied energy of walls, roof and windows in the base model were then calculated to be $1757.32 \mathrm{GJ}$. The calculated value is validated through the study of [7]. The energy embodied in roof is the highest among other elements since the embodied energy is quantified based on unit weight and roof is the heaviest elements as compared to other elements. 


\section{Sensitivity Analysis and Discussion}

As shown in Figure 3(a), it was found that the U-value of roof, walls and windows have strong positive linear relationship with the $\mathrm{OE}$ of building.

These findings are in agreed with the study of [18] and [26] which the higher the U-value of building envelope elements, the more energy is required to maintain the operation of building. Results show that the $\mathrm{U}$-value of roof has the highest gradient slope value respect to $\mathrm{OE}$ of building, followed by walls and windows. This indicates that roof is the most influential design parameter on the $\mathrm{OE}$ of building and therefore in the view of lowering building energy consumption, targeting on lower the $\mathrm{U}$-value of roof to improve the thermal properties of

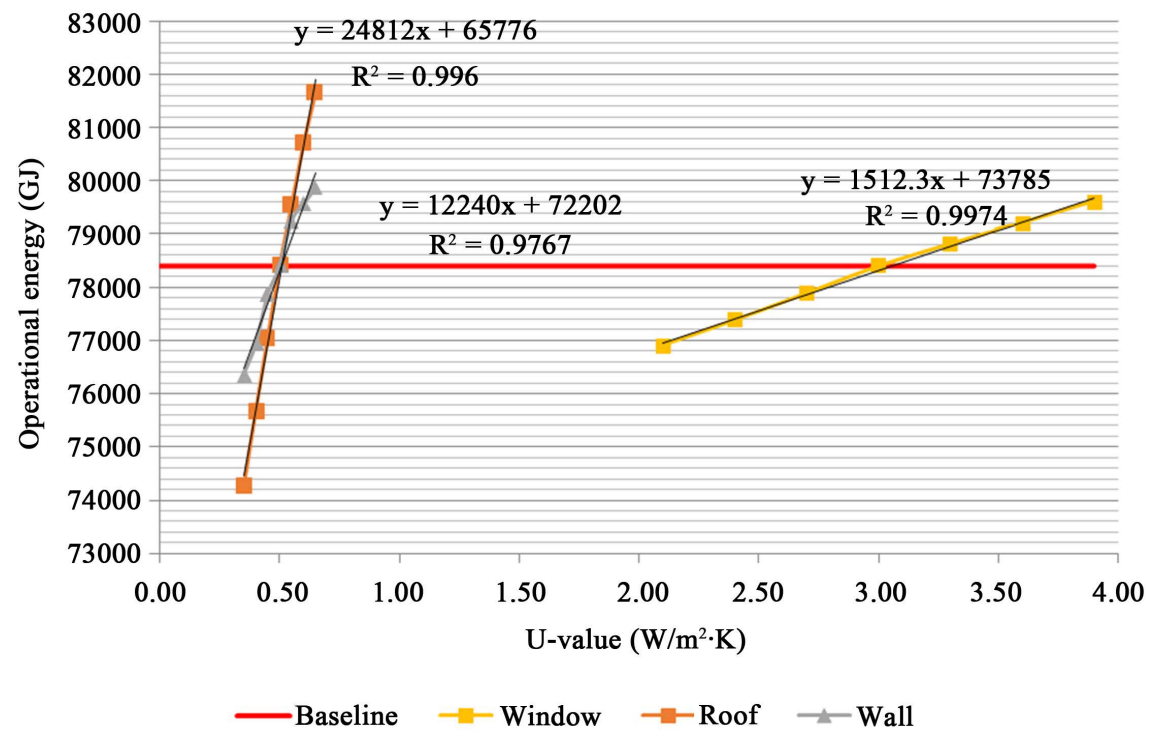

(a)

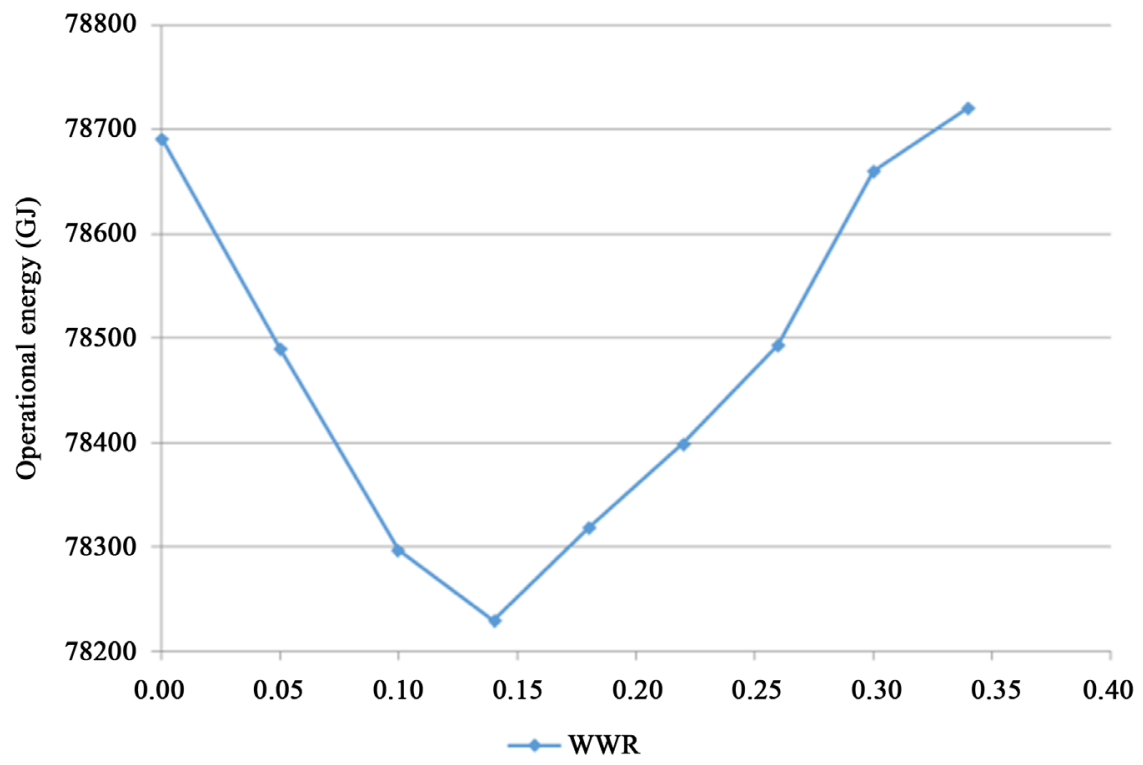

(b)

Figure 3. The impact of U-value of elements and WWR on OE of building. 
building envelope can be priority consideration over other building envelope elements. This is due to the roof has larger area than the walls and windows in this case study; therefore it is reasonable that the influence of roof $U$-value is greater than walls and windows. Figure 3(b) shows the impact of increasing WWR on OE. It is a U-shaped curve with optimum lying at WWR of $14 \%$. The variation of OE with WWR changes is attributed to the change in the area of windows and walls affects the thermal loads of building, such as solar heat gain, heat conduction across envelope element and internal heat gain, and subsequently impact the heating and cooling required by HVAC to maintain thermal comfort within building. Since walls have lower U-value than windows in this research, i.e. better thermal performance, the increase of WWR, which increases the area of windows, would lead to higher cooling and heating loads in building due to windows have higher heat conduction across windows as compared to walls. Other than heat conduction, which is dependent on the external temperature, windows also contribute solar heat gain to building from sun. Solar heat gain is concerned with the area of window and it is desirable during cold season. The amount of solar heat gain is increased with increasing WWR due to larger window area [29] [30].

Performing SA on building envelope is to provide information to facilitate designer in making better decision on prioritizing the optimization target in selecting efficient building envelope design [27] [31]. From design parameter based LSA in previous section, the importance of design parameters to OE of building was understood and it was found that U-value of roof can be the priority target to reduce the $\mathrm{OE}$ of building as compared to other design parameters considered in this research, however this information may not result in an energy-efficient optimization process. This is due to EE of element is considerably increased during the optimization of building envelope while increasing the material consumption to satisfy the target thermal properties and reduce $\mathrm{OE}$ in buildings [2] [15] [32]. Besides, since the elements made up from different materials with its distinct thermal properties and each element comprised different proportion of $\mathrm{EE}$ in the building envelope, it is necessary to understand the uncertainty between thermal properties and $\mathrm{EE}$ of building envelope and subsequently the resulted OE-EE relationship of each envelope element. For example, roof is the element made up the largest portion of building envelope in the case building and the production of roof material in this research contributes significant $\mathrm{EE}$ in the building envelope, hence from the perspective of energy, lowering the $U$-value of roof may not be an efficient practice.

Figure 4(a) and Figure 4(b) illustrate the EE of building envelope respects to $\mathrm{U}$-value of elements and WWR respectively. The EE of building envelope includes those of the walls, windows and roof. It was observed that the lower U-value of element and WWR, the higher EE of building envelope. The EE of building envelope is least sensitive to the variation of window's $U$-value. This is due to the windows contribute insignificant share (3\%) to the EE of building 


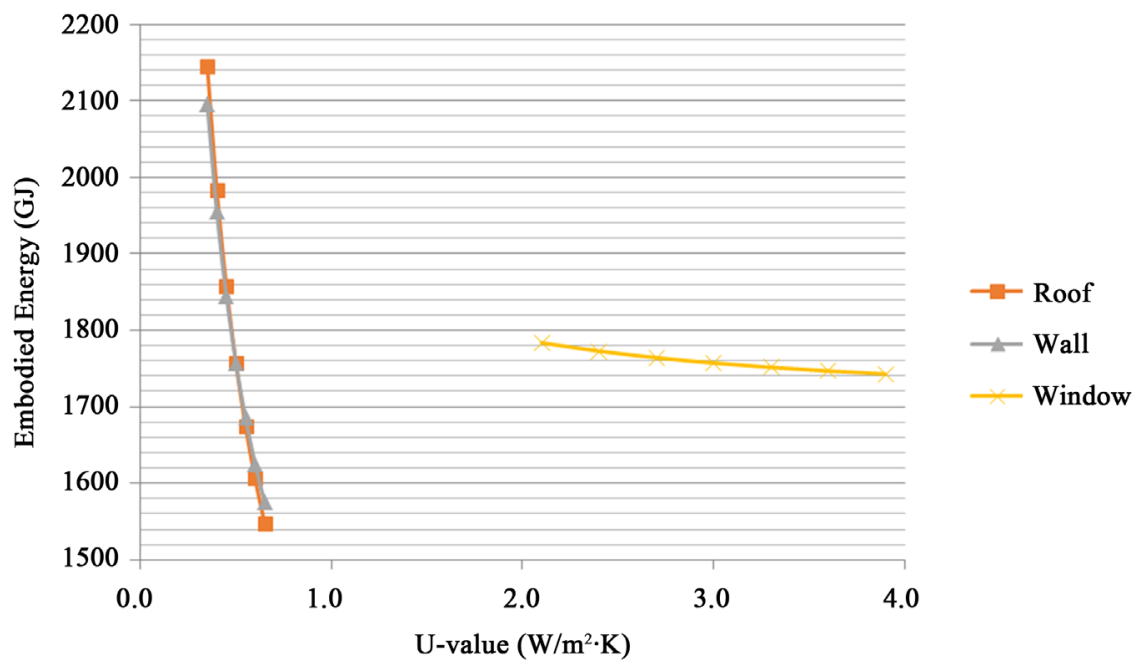

(a)

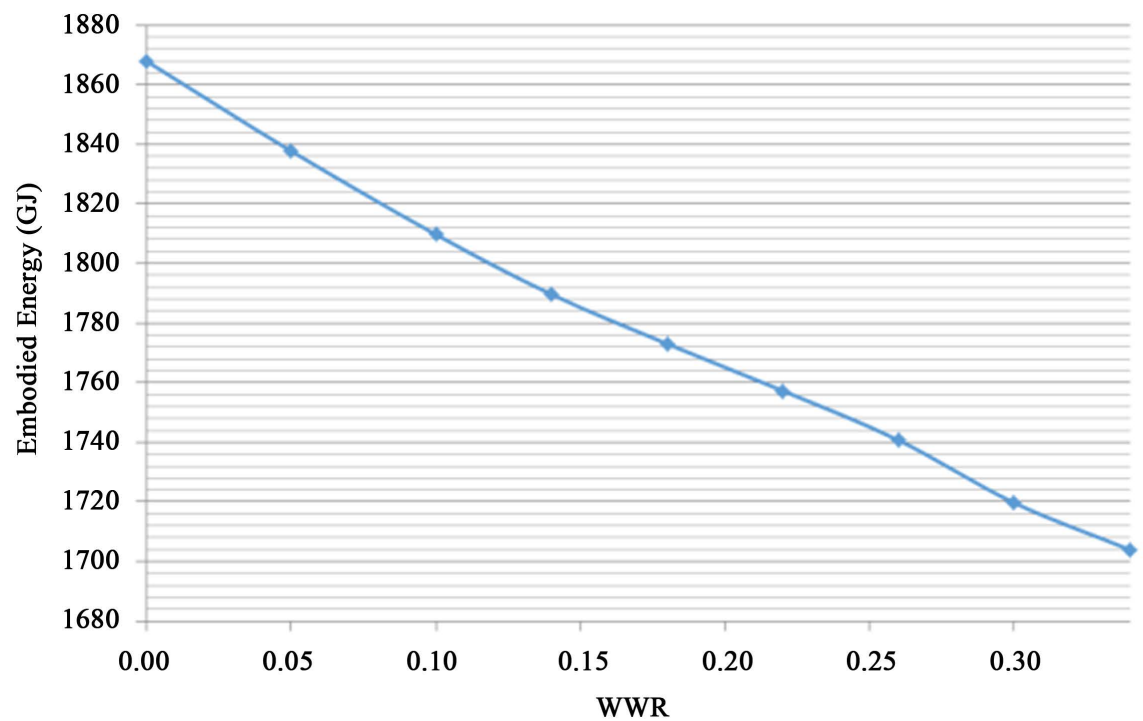

(b)

Figure 4. EE of building envelope respects to $U$-value of elements and WWR.

envelope in this research as compared to other elements; therefore, the impact of window's U-value variation on EE of building envelope is insignificant. This also explained the graph trend of EE versus WWR in Figure 4(b): wall material in this research has significant high EE whereas window material contributes small amount of EE, therefore increases WWR, which also means increases the area of window, will reduce overall $\mathrm{EE}$ of building envelope.

Based on these facts, this research proposed to perform SA based on EE instead of design parameters to determine the impact of $\mathrm{EE}$ variation due to thermal properties change on the $\mathrm{OE}$ of building and relative importance of envelope elements in term of LCE. EE based LSA is performed by calculating EE of building envelope corresponding to the design parameters and comparing the output OE of building on the basis of EE. Figure 5 compares the OE-EE rela- 


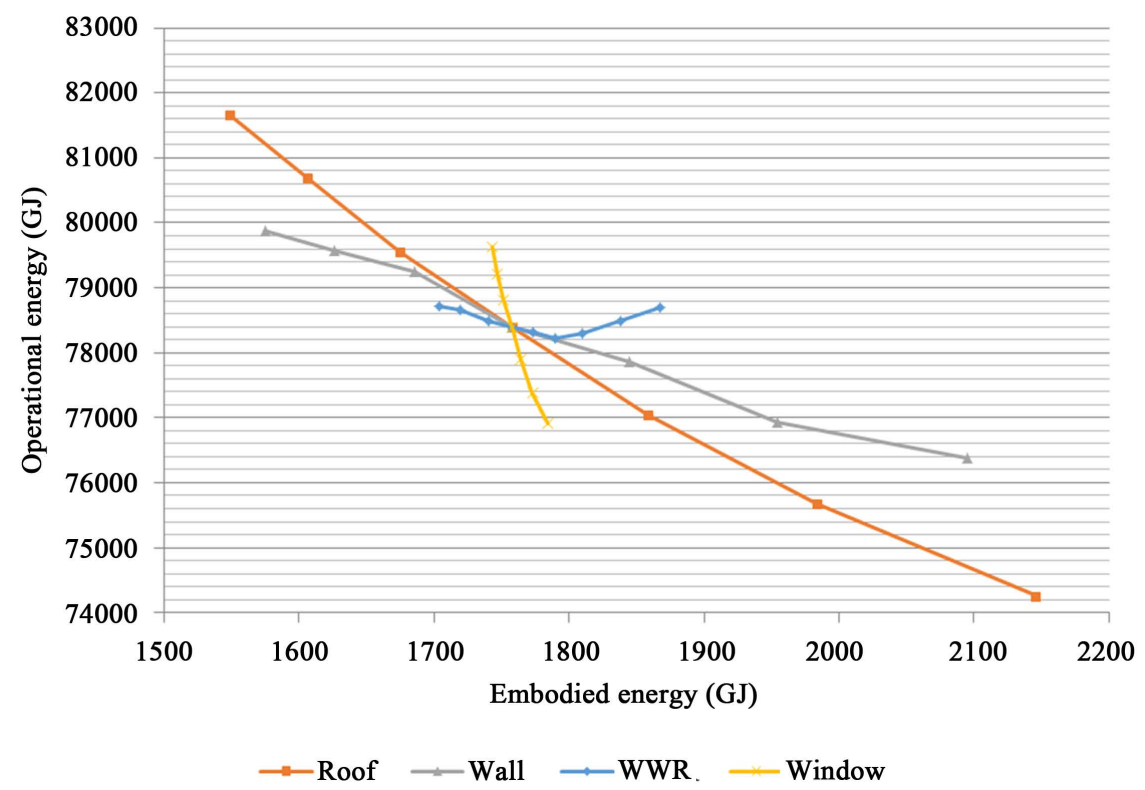

Figure 5. OE-EE relationship of LSA.

tionship of design parameters, which is the sensitivity of OE with respect to change in EE of building envelope resulted from the variation of design parameter. It can be seen that the OE-EE relationship of windows has steepest gradient slope, followed by roof and walls. This means that $\mathrm{OE}$ of building is most sensitive to the variation of EE due to U-value of windows changes. Steeper slope indicates minor increase in EE can lead to significant decrease in OE used in building as compared to those of gentler slope. Although the material of windows have highest energy coefficient among other parameters (Table 3), windows are the most energy-efficient and important parameter to be considered in term of LCE since using slightly more material would lead to considerably less amount of energy used during operational stage. This is attributed to high thermal conductivity $(\mathrm{W} / \mathrm{m} \cdot \mathrm{K})$ of material (air and glass) in double glazing windows which results in thinner glass material required $(<10 \mathrm{~mm})$ to achieve same amount of operational energy saving as compared to other materials $(>200 \mathrm{~mm})$. This concludes that during an optimization process, targeting on the thermal properties of windows would bring the most benefit in term of LCE saving.

Traditionally, the OE-EE relationship is in decreasing trend as in Figure 5, since improvement of thermal properties would increase the material consumption, subsequently increase $\mathrm{EE}$ of building envelope and reduce $\mathrm{OE}$ of building. However, it was observed that the OE-EE relationship of WWR in LSA (Figure 5 ) is neither linear nor monotonic when $U$-value of walls and windows were kept to its base value, i.e. the $\mathrm{OE}$ of building is inconsistent when $\mathrm{EE}$ of building envelope varied with WWR, contrasting with other design parameters. This is due to the thermal load of building changes inconsistently when WWR is varying. Besides, wall and window materials have distinct amount of EE, therefore the variation of WWR, which alters the area of wall and window in building 
envelope, would change the EE of building envelope as well. This brings out the need for Global Sensitivity Analysis (GSO) in order to explore more thoroughly the relationship between WWR and EE of building envelope, subsequently the impact on $\mathrm{OE}$ of building with considering the interactions among design parameters and offer more reliable energy saving practices.

Figure 6 shows the variation of OE with WWR in respect to change in $\mathrm{U}$-value of walls or U-value of windows from its base value, while other parameters were kept constant. It was observed that with the increase of WWR, keeping $\mathrm{U}$-value of windows to base value and changing $\mathrm{U}$-value of walls from base value merely influences the amount of $\mathrm{OE}$ which the higher $\mathrm{U}$-value, more $\mathrm{OE}$ is required (Line 1 and Line 5 in Figure 6). This is due to change in heat conduction across walls associated with the variation of $U$-value and these practices would not change the relationship behavior between $\mathrm{OE}$ and WWR as in Figure 3(b), i.e. OE of building remains inconsistent with the variation of WWR. On the other hand, changing $\mathrm{U}$-value of windows from base value affects trend behavior of relationship between OE and WWR. For the scenarios of lowering U-value of windows and keeping $U$-value of walls to base value, instead of having inconsistent relationship between WWR and OE as in Figure 4(a), the OE of building is decreased with increasing WWR (Line 4 in Figure 6). In contrast, the OE in the scenario with higher $\mathrm{U}$-value of windows is in opposite trend: it is increased with increasing WWR (Line 2 in Figure 6).

This phenomenon is attributed to the variation of thermal load in building with WWR when U-value of walls and windows changed. In the scenarios of lowering $\mathrm{U}$-value of windows (Line 4 in Figure 6), the heat loss across windows through conduction during cold season is reduced, which result in lower heating load required than those in base scenarios (Figure 3(b)). During hot season, the reduction of heat gain across windows with lower U-value through conduction

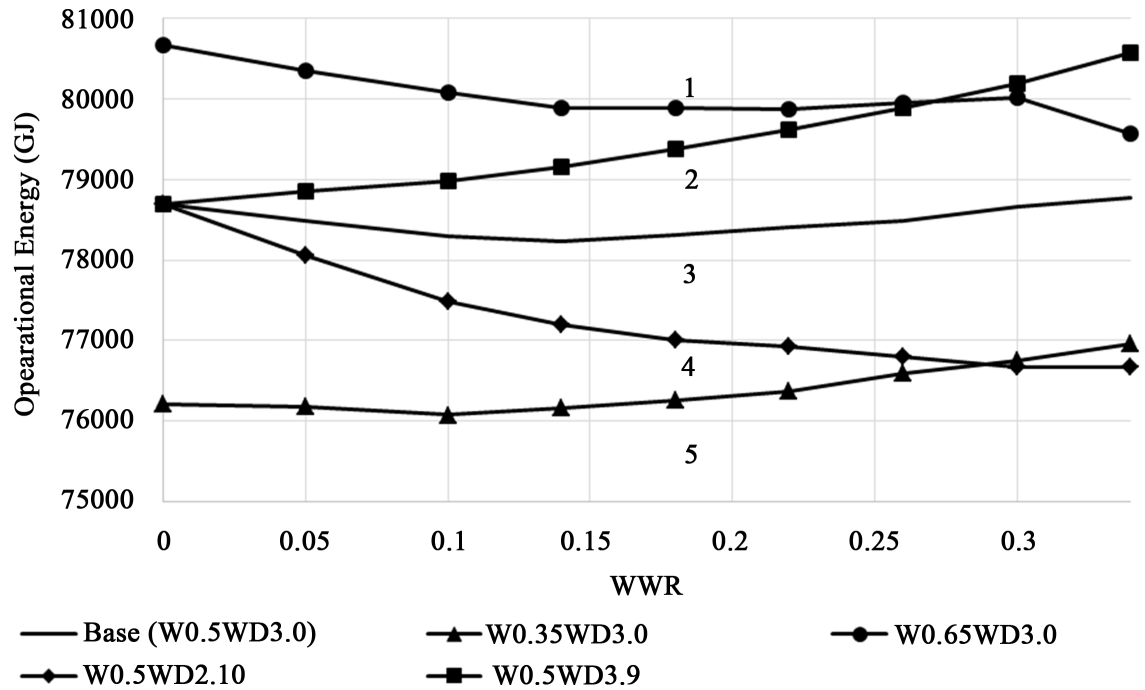

Figure 6. The variation of OE with WWR with respect to change in U-value of walls or U-value of windows. 
has compensate the increasing solar heat gain with WWR, therefore the cooling load required is also reduced. As a result, the overall $\mathrm{OE}$ required with increasing WWR is in a decreasing trend. While for the scenarios with higher U-value of windows (Line 2 in Figure 6), in the event of increasing WWR, the increasing degree of solar heat gain through windows is insufficient to offset the increasing heat loss across windows with poorer thermal performance during cold season and the heat gain across windows with higher $\mathrm{U}$-value is higher during hot season, therefore more heating and cooling loads are required when windows has higher U-value, subsequently OE of building is increased with increasing WWR, i.e. the relationship between $\mathrm{OE}$ and WWR is in an increasing trend.

GSA was also performed to investigate the sensitivity of design parameters based on EE. Therefore, the corresponding EE value respect to WWR and $\mathrm{U}$-value variation was calculated and as plotted in Figure 7. It was noticed that WWR has inverse relationship with EE of building envelope, identical to the findings in Figure 4(b)). When the U-value of walls changes from base value, EE of building envelope varied significantly from base scenarios whereas it varied slightly when the U-value of windows changes. This is due to walls constitute greater proportion than windows in the building envelope; therefore, more materials are needed to vary its thermal properties.

From the calculated EE values, GSA was interpreted as the sensitivity of OE with respect to change in $\mathrm{EE}$ of building envelope by transforming the relationship between OE and WWR in Figure 6 into OE-EE relationship, as illustrated in Figure 8, for the purpose to observe and compare the energy-efficiency of difference OE-EE relationships. As WWR has inverse relationship with EE of building envelope, the resulted OE-EE relationship is in the opposite trend to the OE-WWR relationship.

The findings from Figure 8 are as summarized in Table 4. For scenarios of lowering U-value of windows, the OE-EE relationship of WWR is in an increase-
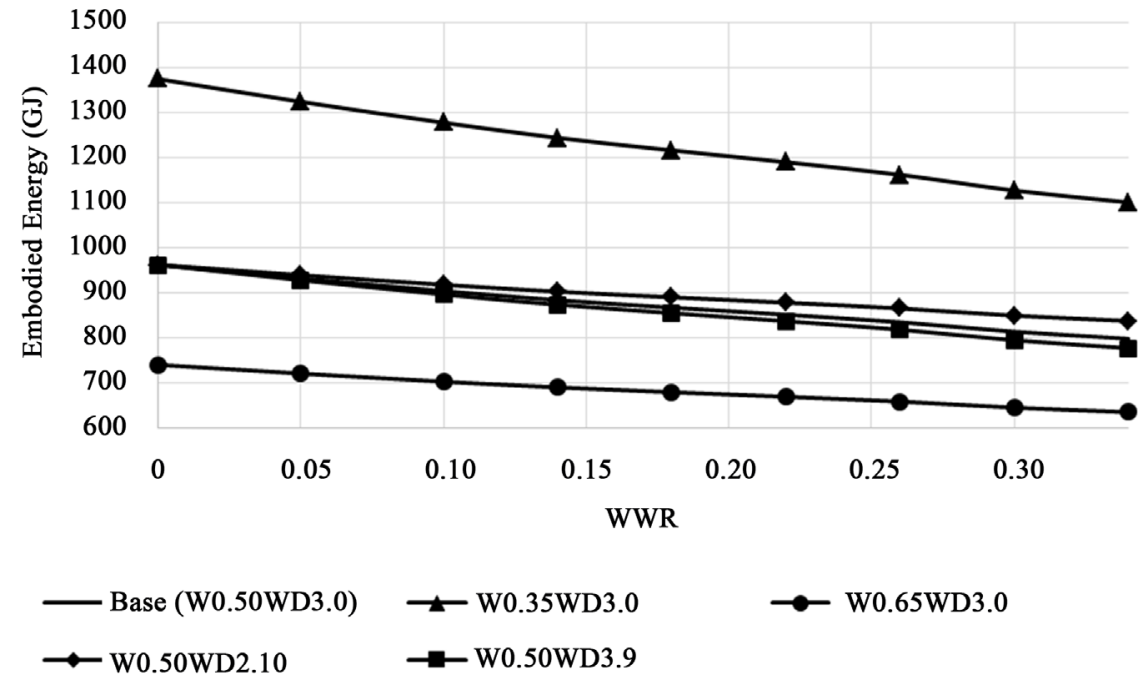

Figure 7. EE of building envelope respect to WWR and U-value variation. 


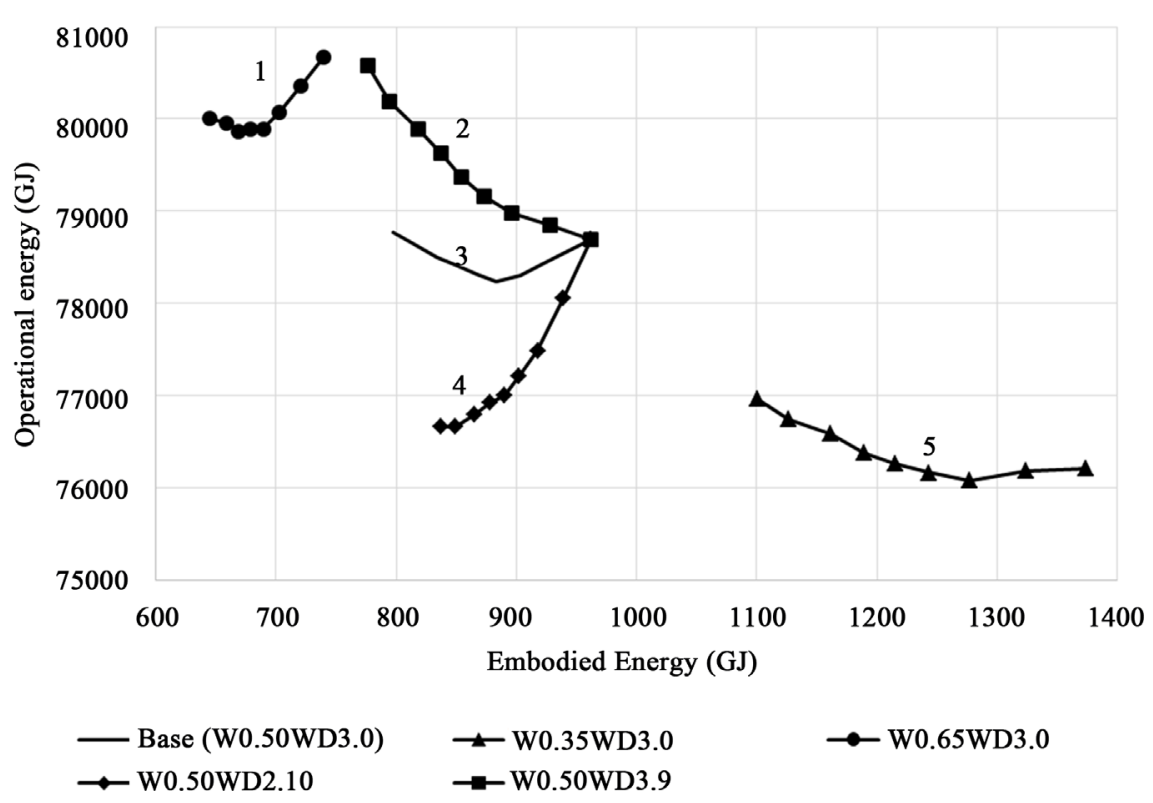

Figure 8. OE-EE relationship of GSA.

Table 4. OE-EE relationship of WWR with changing U-value of windows or walls.

\begin{tabular}{cccc}
\hline \multicolumn{2}{c}{ Scenario } & & OE-EE relationship \\
U-value of Windows & U-value of Walls & & Decreasing trend \\
Higher & Base value & & Increasing trend \\
Lower & Base value & No trend \\
Base value & Base value & No trend \\
Base value & Higher & No trend \\
Base value & Higher & &
\end{tabular}

ing trend (Line 4 in Figure 8). This is due to the effectiveness of windows with lower $\mathrm{U}$-value in reducing the thermal load of building. On the other hand, it comprised relatively lower EE in building envelope as compared to walls, therefore when WWR increased, i.e. replacing walls with windows in building envelope, the overall $\mathrm{EE}$ of building envelope is reduced. As a result, the resulted $\mathrm{OE}-\mathrm{EE}$ relationship is positive, which $\mathrm{OE}$ is decreased (increased) when EE decreased (increased). While for the scenarios with higher $U$-value of windows, the poor thermal performance of windows has led to higher thermal load of building with increasing WWR, OE of building is then increased with decreasing EE (Line 2 in Figure 8). Therefore, when varying WWR during design stage, targeting on thermal properties of windows would bring noticeable impact to both EE of building envelope and OE of building and help to develop an energy-efficient design scheme that can reduce the overall LCE of building.

GSA was performed on total 62 scenarios with the variation of WWR, U-value of windows and U-value of walls together. Standard Regression Coefficient (SRC) 
was chosen as the sensitivity indicator for GSA in this research due to its ability to provide the information of model behaviour and it is useful to understand the strength of the correlation degree between input and output of a linear model [6].

The sensitivity results are as shown in Figure 9 by varying WWR, U-value of windows and walls together. Positive value means that the OE-EE relationship is positive (increasing trend), i.e. with the increase (decrease) of EE, the OE is increased (decreased), while negative value of SRC is that the variation of EE and $\mathrm{OE}$ tend to go in opposite direction, i.e. the $\mathrm{OE}$ is increased (decreased) when $\mathrm{EE}$ is decreased (increased). The higher the SRC value is, the stronger the influence on OE. From the view of LCE, using less material during construction stage (small $\mathrm{EE}$ ) and leads to less energy required in the later operational stage (small $\mathrm{OE}$ ) is the most efficient energy saving practice, therefore scenarios with positive value of SRC that have lower EE and OE as compared to energy baseline are more energy-efficient practice than those of negative value. From Figure 9, it was observed that the OE-EE relationships of WWR in scenarios with lower $\mathrm{U}$-value of windows $\left(2.1 \mathrm{~W} / \mathrm{m}^{2} \cdot \mathrm{K}\right)$ have positive $\mathrm{SRC}$ value, i.e. OE is reduced when EE decreased (WWR increased), and the degree of influence is varied slightly with increasing U-value of walls. This means that during WWR variation, thermal properties of walls have insignificant impact on OE-EE relationship of WWR and lowering U-value of windows is the most influential energyefficient practice that brings positive impact to the overall LCE of building. In contrast, the OE-EE relationships of WWR in the scenarios with higher $U$-value of windows have negative SRC value and the highest value was observed when $\mathrm{U}$-value of walls is lower. However, the practices in scenario with negative SRC value are not of interest in this research since these practices are less energy-

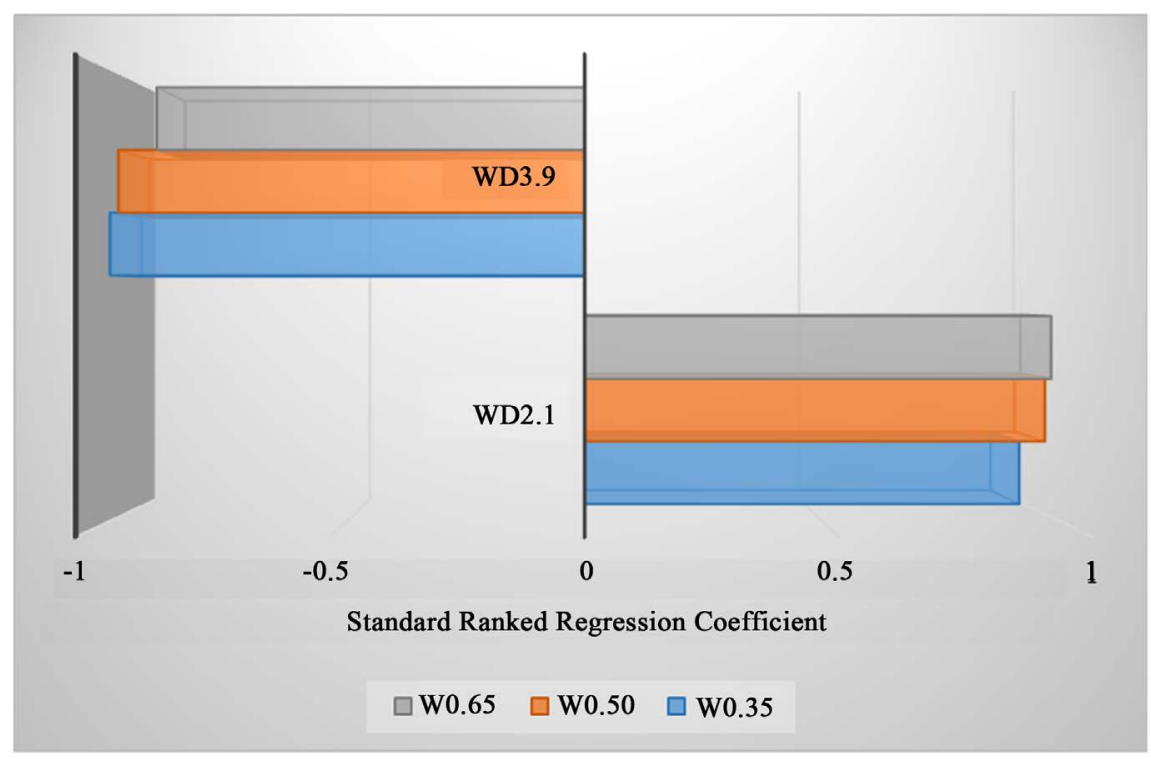

Figure 9. Sensitivity based on SRC. 
efficient and should not be the priority during optimization process. The findings from EE based LSA and GSA of OE with respect to the variation of WWR, $\mathrm{U}$-value of windows and $\mathrm{U}$-value of walls are summarized as: 1) $\mathrm{OE}$ of building is most sensitive to the variation of $\mathrm{EE}$ due to $\mathrm{U}$-value of windows changes and least sensitive to the variation of EE due to U-value of walls changes; 2) Thermal properties of walls have insignificant impact on OE-EE relationship of WWR whereas changing thermal properties of windows affects the OE-EE relationship behavior or WWR; 3) Lowering U-value of windows brings positive impact to the OE-EE relationship of WWR; and 4) Increase U-value of windows brings negative impact to the OE-EE relationship of WWR. Based on these findings, it was concluded that targeting on thermal properties of windows when varying WWR brings noticeable impact to both $\mathrm{EE}$ of building envelope and $\mathrm{OE}$ of building. Therefore, the suggestions for designer in selecting efficient building envelope designs are summarized as: 1) Minimize $U$-value of windows and maximize U-value of walls during design stage; 2) Minimize U-value of windows when consider increasing the WWR of building; and 3) Maximize U-value of windows when consider decreasing the WWR of building.

\section{Conclusion and Recommendations}

In this research, the impact of building envelope elements, including walls, windows and roof, on building energy consumption was investigated with the aid of BIM tools as platform and the envelope element that has the most influential impact on building energy consumption was investigated by performing SA on a case study of manufactory plant in Suzhou. The design parameter in this research focused on the thermal properties of envelope element and WWR. Due to the envelope elements have their distinct thermal properties and comprised of different proportions in building envelope, the SA was proposed to carry out based on EE instead of design parameters, which measure and compare the correlation degree between $\mathrm{EE}$ and $\mathrm{OE}$ in building for each envelope element. Throughout EE based SA, the uncertainties between thermal properties and EE of building envelope were revealed, subsequently the resulted OE-EE relationships of envelope element were then compared to understand the relative important of envelope element on building performance in term of EE. The outcomes of this research provide information to facilitate designer to make better decision on prioritizing the optimization target in selecting efficient building envelope design.

\section{References}

[1] Sakar, A. and Bose, S. (2016) Exploring Impact of Opaque Building Envelope Components on Thermal and Energy Performance of Houses in Lower Western Himalayans for Optimal Selection. Journal of Building Engineering, 7, 170-182. https://doi.org/10.1016/j.jobe.2016.06.009

[2] Huang, J., Lv, H.L., Gao, T., Feng, W., Chen, Y.X. and Zhou, T. (2014) Thermal Properties Optimization of Envelope in Energy-Saving Renovation of Existing Pub- 
lic Buildings. Energy and Buildings, 75, 504-510. https://doi.org/10.1016/j.enbuild.2014.02.040

[3] Pikas, E., Thalfeldt, M. and Kurnitski, J. (2014) Cost Optimal and Nearly Zero Energy Building Solutions for Office Buildings. Energy and Buildings, 74, 30-42. https://doi.org/10.1016/j.enbuild.2014.01.039

[4] Liu, S., Meng, X. and Tam, C. (2015) Building Information Modelling Based Building Design Optimization for Sustainability. Energy and Buildings, 105, 139-153. https://doi.org/10.1016/j.enbuild.2015.06.037

[5] IPCC Fourth Assessment Report: Climate Change 2007, Switzerland: Intergovernmental Panel on Climate Change.

http://www.ipcc.ch/publications and data/ar4/wg3/en/ch6s6-4-14.html

[6] Nguyen, A. and Reiter, S. (2015) A Performance Comparison of Sensitivity Analysis Methods for Building Energy Models. Building Simulation, 8, 651-664.

https://doi.org/10.1016/j.enbuild.2015.06.037

[7] Praseeda, K., Venkatarama, I., Reddy, B.V. and Mani, M. (2016) Embodied and Operational Energy of Urban Residential Buildings in India. Energy and Buildings, 110, 211-219. https://doi.org/10.1016/j.enbuild.2015.09.072

[8] Mohammad, S. and Shea, A. (2013) Performance Evaluation of Modern Building Thermal Envelope Designs in the Semi-Arid Continental Climate of Tehran. Buildings, 3, 674-688. https://doi.org/10.3390/buildings3040674

[9] Ibn-Mohammed, T., Greenough, R., Taylor, S., Ozawa-Meida, L. and Acquaye, A. (2013) Operational vs. Embodied Emissions in Buildings-A Review of Current Trends. Energy and Buildings, 66, 232-245. https://doi.org/10.1016/j.enbuild.2013.07.026

[10] Azari, R., Garshasbib, S., Aminia, P., Rashed-Alia, H. and Mohammadi, Y. (2016) Multi-Objective Optimization of Building Envelope Design for Life Cycle Environmental Performance. Energy and Buildings, 126, 524 -534. https://doi.org/10.1016/j.enbuild.2013.07.026

[11] Department of Energy (2016) Research \& Development Roadmap for Emerging Window and Building Envelope Technologies. DOE, Washington DC. http://energy.gov/sites/prod/files/2014/02/f8/BTO windows and envelope report 3.pdf

[12] Goia, F., Time, B. and Gustavsen, A. (2015) Impact of Opaque Building Envelope Configuration on the Heating and Cooling Energy Need of a Single Family House in cold Climates. Energy Procedia, 78, 2626-2631. https://doi.org/10.1016/j.enbuild.2013.07.026

[13] Cole, R. and Kernan, P.C. (1996) Life Cycle Energy Use in Office Buildings. Building and Environment, 31, 307-317. https://doi.org/10.1016/0360-1323(96)00017-0

[14] Adalberth, K. (1997) Energy Use during the Life Cycle of Single-Unit Dwellings: Examples. Building and Environment, 32, 321-329. https://doi.org/10.1016/S0360-1323(96)00069-8

[15] Wadsö, L., Karlsson, J. and Tammo, K. (2012) Thermal Properties of Concrete with Various Aggregates. Cement and Concrete Research Manuscript Draft, Lund University, Lund.

[16] Tucker, S. (2000) Embodied and Lifetime Energies in the Built Environment. http://www.dbce.csiro.au/ind-serv/brochures/embodied/embodied.htm

[17] Thormark, C. (2002) A Low Energy Building in a Life Cycle-Its Embodied Energy, Energy Need for Operation and Recycling Potential. Building and Environment, 37, 
429-435. https://doi.org/10.1016/S0360-1323(01)00033-6

[18] Ioannou, A. and Itard, L. (2015) Energy Performance and Comfort in Residential Buildings: Sensitivity for Building Parameters and Occupancy. Energy and Buildings, 92, 216-233. https://doi.org/10.1016/j.enbuild.2015.01.055

[19] Hammond, G. and Jones, C. (2008) Embodied Energy and Carbon in Construction Materials. Proceedings of the Institution of Civil Engineers-Energy, 161, 87-98. https://doi.org/10.1680/ener.2008.161.2.87

[20] Dowd, R.M. and Mourshed, M. (2015) Low Carbon Buildings: Sensitivity of Thermal Properties of Opaque Envelope Construction and Glazing. Energy Procedia, 75, 1284-1289. https://doi.org/10.1016/j.egypro.2015.07.189

[21] Hussain, A. (2015) Significance of Embodied Energy and U-Value in Green Buildings: An Overview. International Conference on Technologies for Sustainability-Engineering, Information Technology, Management and the Environment, Faridabad, 28 November 2015.

[22] Chinese National Standard (2015) GB50189-2015-Design Standard for Energy Efficiency of Public Buildings.

[23] Ochoa, C.E., Aries, M.B.C., van Loenen, E.J. and Hensen, J.L.M. (2012) Considerations on Design Optimization Criteria for Windows Providing Low Energy Consumption and High Visual Comfort. Applied Energy, 95, 238-245. https://doi.org/10.1016/j.apenergy.2012.02.042

[24] Harwell, A. (2016) Windows Technical Background Report Windows. European Commission, Brussels.

[25] Hassan, A.S. and Al-Ashwal, N.T. (2015) Impact of Building Envelope Modification on Energy Performance of High-Rise Apartments in Kuala Lumpur, Malaysia. International Transaction Journal of Engineering, Management and Applied Sciences \& Technologies, 3, 91-105.

[26] Yu, J., Tian, L., Yang, C., Xu, X. and Wang, J. (2013) Sensitivity Analysis of Energy Performance for High-Rise Residential Envelope in Hot Summer and Cold Winter Zone of China. Energy and Buildings, 64, 264-274. https://doi.org/10.1016/j.enbuild.2013.05.018

[27] Lam, C. and Hui, C.M. (1996) Sensitivity Analysis of Energy Performance of Office Buildings. Building and Environment, 31, 27-39. https://doi.org/10.1016/0360-1323(95)00031-3

[28] Scheer, D. (2013) Advanced Energy Analysis with Green Building Studio DOE2 and EnergyPlus Support.

http://autodesk.typepad.com/bpa/2013/03/advanced-energy-analysis-with-green-bu ilding-studio-doe2-and-energyplus-support.html

[29] Autodesk (2015) Thermal Loads. http://sustainabilityworkshop.autodesk.com/buildings/thermal-loads

[30] Wulfinghoff, D.R., Rawal, R., Garg, V. and Mathur, J. (2009) Building Envelope. http://pdf.usaid.gov/pdf docs/Pnado833.pdf

[31] Heiselberg, A., Brohus, H., Hesselholt, A., Rasmussen, H., Seinre, E. and Thomas, S. (2009) Application of Sensitivity Analysis in Design of Sustainable Buildings. Renewable Energy, 34, 2030-2036. https://doi.org/10.1016/j.renene.2009.02.016

[32] Harvey, L.D.D. (2009) Reducing Energy Use in the Buildings Sector: Measures, Costs, and Examples. Energy Efficiency, 2, 139-163.

https://doi.org/10.1007/s12053-009-9041-2 
Submit or recommend next manuscript to SCIRP and we will provide best service for you:

Accepting pre-submission inquiries through Email, Facebook, LinkedIn, Twitter, etc. A wide selection of journals (inclusive of 9 subjects, more than 200 journals)

Providing 24-hour high-quality service

User-friendly online submission system

Fair and swift peer-review system

Efficient typesetting and proofreading procedure

Display of the result of downloads and visits, as well as the number of cited articles Maximum dissemination of your research work

Submit your manuscript at: http://papersubmission.scirp.org/

Or contact ojce@scirp.org 